\title{
X-RAY ANALYSIS OF ROUGH SURFACES AT LOW ENERGY
}

\author{
Pierre Hovington, Marin Lagacé, Lisa Rodrigue \\ Hydro-Québec Research Institut, 1800 Boul. Lionel-Boulet, Varennes, Québec, J3X 1S1, Canada
}

With the advent of Field Emission Gun SEMs (FE-SEM) most of the efforts have been spent toward low energy analysis $(\mathrm{Eo}<5 \mathrm{keV})$. However, at these energies, because of the very small interaction volume $(125 \mathrm{~nm}$ at $5 \mathrm{keV}$ compared to $1460 \mathrm{~nm}$ at $20 \mathrm{keV}$ for $\mathrm{Cu}$ ), experimental measurements are strongly affected by surface roughness and chemistry. Hence, surface quality can limit analysis reliability. It is then of primary importance to determine the maximum roughness tolerable in order to get good quantitative results at low energy. The effect of surface roughness having been mainly focussed on high energy X-ray $(>10 \mathrm{keV})[1][2]$, this work will study the effect of surface roughness on X-ray analysis accuracy at low energy.

Coper and titanium were used to carry out this work. Samples were polished up to colloidal silica to obtain a "mirror finish" surface. The arithmetic roughness (RA) measured was of $0.13 \mu \mathrm{m}$. Surface roughness is measured with an optical profilometer. Lines of $4 \mathrm{~mm}$ in length are scanned on the surface The measurements points along the lines are separated by $500 \mathrm{~nm}$. In order to limit measurement noise, nine passes are made for each line and the result at each points are averaged. Twelve such lines were scanned on the surface of each sample. The RA was then calculated for each line and then averaged for all twelve lines. Samples of different roughness were obtained by sand blasting at different grazing angles. A sample was also obtained by polishing it up to a 320 grit $\mathrm{SiC}$ paper. Figure 1 shows the complete X-ray spectra for the different roughness $\mathrm{Cu}$ samples. The spectra were taken at a beam energy (Eo) of $20 \mathrm{keV}$ in a raster mode with a magnification of 450X. All other experimental conditions were kept constant. The X-ray system used was a $30 \mathrm{~mm}^{2} \mathrm{Si}(\mathrm{Li})$ detector (Oxford, ISIS) with a take off angle of $30^{\circ}$. The SEM used was a Hitachi S-4700 FE-SEM. We clearly see in figure 1 the effect of roughness on the BG intensity for energies around $3 \mathrm{keV}$. Figure 2 shows that the relative error on the $\mathrm{Cu} \mathrm{L}$ peak $(\mathrm{Eo}=5 \mathrm{keV})$ for a rough surface $(\mathrm{RA}=0.89 \mu \mathrm{m})$ compared to that of a flat surface $(\mathrm{RA}=0.13 \mu \mathrm{m})$ can be significantly decreased by using a linescan or raster mode to average out the roughness effects caused by abnormal absorption and mass effect. This conclusion is confirmed by both the $\mathrm{Cu} \mathrm{L}$ peak and the peak to backgound (P/B) ratios. The P/B ratio was calculated as the total intensity of the $\mathrm{Cu} \mathrm{L} \alpha$ peak (by fitting a gaussian curve) divided by the background (BG) intensity at the maximum intensity energy of the $\mathrm{Cu} \mathrm{L}$ peak. The BG was fitted using a $3^{\text {rd }}$ degree polynomial. The BG and peaks $(\mathrm{Cu} \mathrm{L} \alpha$ and $\mathrm{Cu} \mathrm{Ll)} \mathrm{were} \mathrm{simultaneously} \mathrm{fitted} \mathrm{using} \mathrm{a} \mathrm{non} \mathrm{linear} \mathrm{algorithm} \mathrm{[3].}$

The effect of surface roughness on X-ray emission at $5 \mathrm{keV}$ and $20 \mathrm{keV}$ can be clearly seen on Figure 3 and 4. The analyses were performed in raster mode at $450 \mathrm{X}$ to average out errors. Both the net intensity $(\mathrm{Cu} \mathrm{L}$ at $5 \mathrm{keV}, \mathrm{Cu} \mathrm{K}$ and $\mathrm{Cu} \mathrm{L}$ at $20 \mathrm{keV})$ and the $\mathrm{P} / \mathrm{B}$ ratios are plotted. Figure 3 clearly shows that, for surface roughness greater than $0.85 \mu \mathrm{m}$, significant errors can be made even when using the $\mathrm{P} / \mathrm{B}$ ratio method. This is expected since the $\mathrm{P} / \mathrm{B}$ ratio at low energy is less accurate than at high energy because of the difficulty to accurately fit the BG which is non linear at low energy. Furthermore, there is a high probability of convolution with elemental peaks leaving a vast energy range where no reliable BG signal can be used for interpolation (see Figure 1). Finally, at low energy, part of the BG can be generated in regions away from the beam by the increase in backscattered electrons (remote excitation). Interestingly, at high energy (namely at the $\mathrm{Cu} \mathrm{K}$ peak), the signal is not significantly affected by roughness as high as $3.5 \mu \mathrm{m}$. It is also interesting to note that roughness effects stabilize for roughness exceeding $2 \mu \mathrm{m}$ (see Figure 3 and 4 ). This will be confirmed by using other parametrization techniques for surface roughness such as average peak-to-peak variation, FFT and fractal analysis [4 ].

In conclusion, X-ray emission at low energy is significantly impacted by surface roughness even when spectra are acquired in raster mode (image mode). The roughness effects at low energy could not be accurately corrected by the P/B ratio. Effort will be spent finding the methods limits and the maximum roughness tolerable to perform low energy X-ray quantitative analysis reliably. 


\section{References}

[1] Scanning Electron Microscopy and X-Ray Microanalysis, $2^{\text {nd }}$ edition, 1992, Plenum Press, p.484

[2] Gauvin, R. and Lifshin E. (2000), Mikrochim. Acta 132, pp 201-204

[3] Van Espen, P. et al, (1977), Nucl. Instr. And Meth, 142, pp. 243-250

[4] John C. Russ, Fractal Surfaces, Plenum Press, New York, 1994.

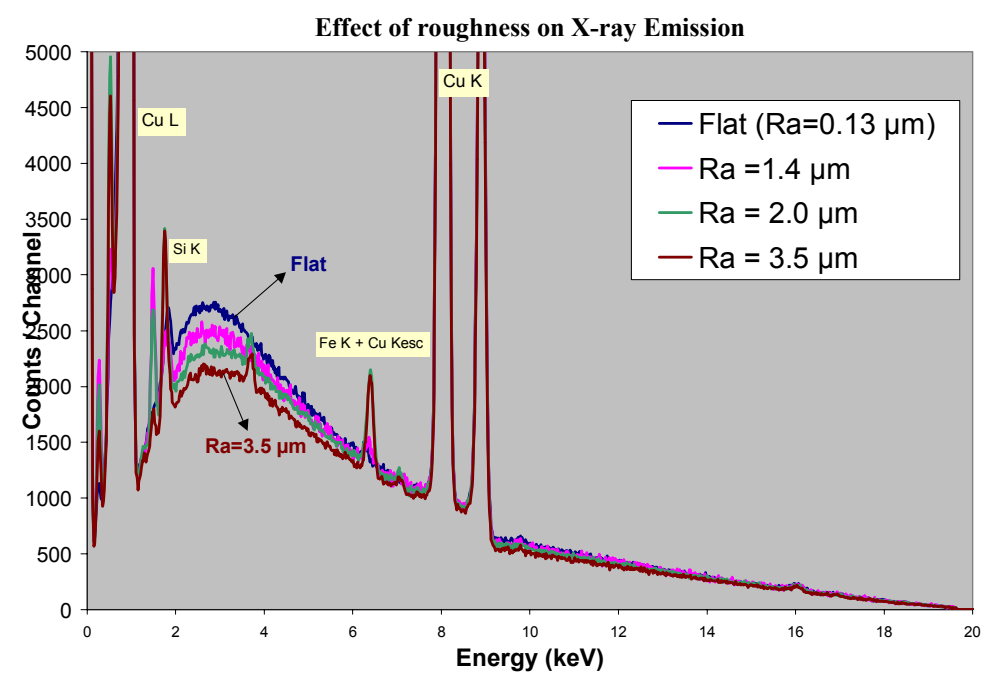

Figure 1: Complete $\mathrm{X}$-ray spectra for the different roughness of $\mathrm{Cu}$ samples $(\mathrm{Eo}=20 \mathrm{keV})$
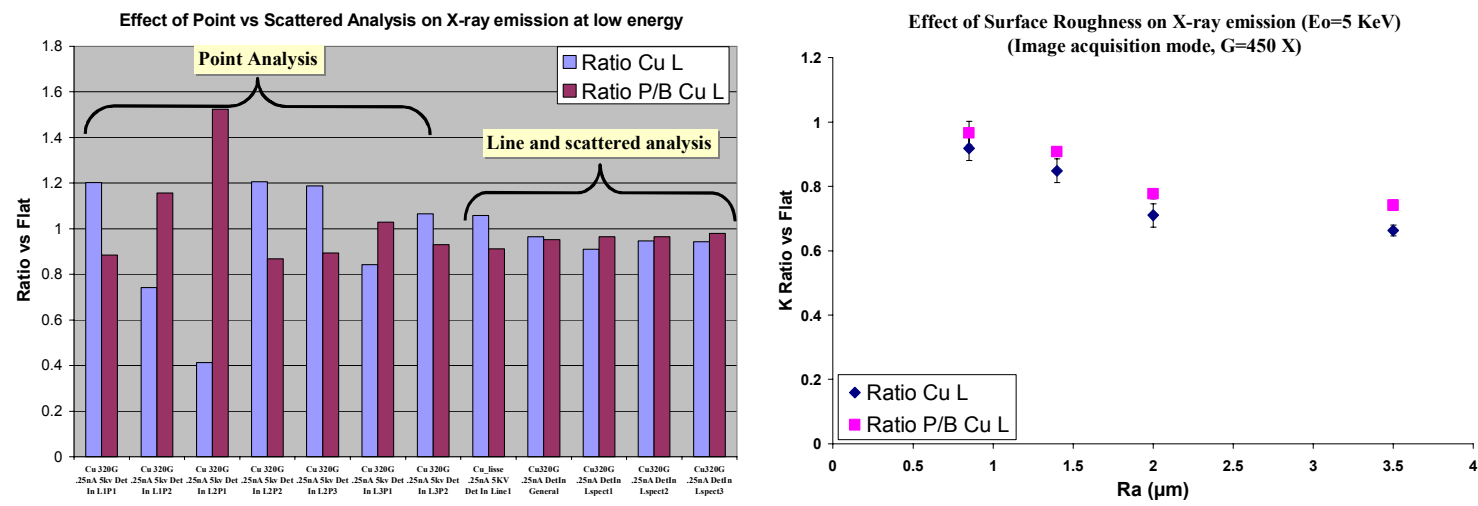

Fig. 2

Fig. 3

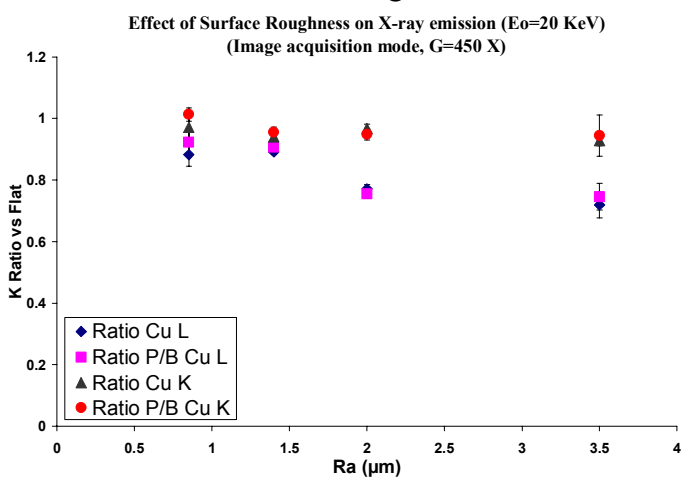

Fig. 4

Figure 2: Comparaison of $\mathrm{K}$ ratios (vs flat surface) for both $\mathrm{Cu} \mathrm{L}$ and $\mathrm{P} / \mathrm{B}$ at the $\mathrm{Cu} \mathrm{L}$ acquired using point analysis, line scan and image mode

Figure 3: $\mathrm{K}$ ratios (vs flat surface) as a function of $\mathrm{Ra}$ for $\mathrm{Cu}$ at $5 \mathrm{keV}$

Figure 4: $\mathrm{K}$ ratios (vs flat surface) as a function of $\mathrm{Ra}$ for $\mathrm{Cu}$ at $20 \mathrm{keV}$ 